\title{
Effect of an emergency department sepsis protocol on time to antibiotics in severe sepsis
}

\author{
Marc Francis, MD; ${ }^{*}$ Tom Rich, MD; ${ }^{*}$ Tyler Williamson, BSc; ${ }^{\dagger}$ Daniel Peterson, MD, $\mathrm{PhD}^{\ddagger}$
}

\section{ABSTRACT}

Objective: We sought to evaluate the time to antibiotics for emergency department (ED) patients meeting criteria for severe sepsis before and after the implementation of an ED sepsis protocol. Compliance with published guidelines for time to antibiotics and initial empiric therapy in sepsis was also assessed.

Methods: A retrospective chart review was conducted. Emergency department patient encounters with International Classification of Diseases codes related to severe infections were screened during a 3-month period before and after the implementation of a sepsis protocol. Encounters meeting criteria for severe sepsis were further assessed. The time to initiation of antibiotics was determined as well as the initial choice of antimicrobial therapy based on the presumed source of infection.

Results: We reviewed 213 unique ED patient encounters meeting criteria for severe sepsis. Analysis of the period before implementation showed a median time from the time criteria for severe sepsis were met to delivery of antibiotics of 163 minutes (95\% confidence interval $[\mathrm{Cl}] 124$ to $210 \mathrm{~min}$ ). Analysis of the period after implementation of the protocol revealed a median time of 79 minutes $(95 \% \mathrm{Cl} 64$ to $94 \mathrm{~min})$, representing an overall reduction of 84 minutes $(95 \% \mathrm{Cl} 42$ to $126 \mathrm{~min})$. Before the implementation of the protocol, $47 \%$ of patients received correct antibiotic coverage for the presumed source of infection in compliance with locally published guidelines. After the initiation of the protocol, 73\% received appropriate initial antibiotics, for an overall improvement of $26 \%$.

Conclusion: A guideline-based ED sepsis protocol for the evaluation and treatment of the septic patient appears to improve the time to administration of antibiotics as well as the appropriateness of initial antibiotic therapy in patients with severe sepsis.

Keywords: sepsis, severe sepsis, septic shock, emergency medicine, quality improvement, emergency department

\section{RÉSUMÉ}

Objectif : Nous avons cherché à évaluer le délai d'administration d'antibiotiques chez les patients à l'urgence répondant aux critères de sepsis sévère, avant et après la mise en œuvre d'un protocole de prise en charge des états septiques dans les service d'urgence. Nous avons aussi évalué le respect des lignes directrices publiées quant au délai d'administration d'antibiotiques et au traitement empirique initial en cas de sepsis.

Méthodes: Nous avons réalisé une étude rétrospective des dossiers médicaux. Nous avons passé en revue, au cours d'une période de 3 mois précédant et suivant la mise en application d'un protocole de prise en charge des états septiques, les dossiers des patients dont l'état était associé à un code relatif à une infection grave selon la Classification internationale des maladies. Les patients répondant aux critères de sepsis sévère ont fait l'objet d'une évaluation plus poussée. Nous avons mesuré le délai d'administration d'antibiotiques ainsi que le choix initial d'antibiothérapie, selon la source présumée d'infection.

Résultats : Nous avons examiné 213 dossiers de patients à I'urgence répondant aux critères de sepsis sévère. L'analyse de la période précédant la mise en œuvre du protocole a révélé un délai médian de 163 minutes (intervalle de confiance à $95 \%$ [IC], de 124 à $210 \mathrm{~min}$ ) entre la détermination de la satisfaction aux critères de sepsis sévère à l'administration d'antibiotiques. L'analyse de la période suivant la mise en œuvre du protocole a révélé un délai médian de 79 minutes (IC à $95 \%$, de 64 à $94 \mathrm{~min}$ ), soit une réduction globale de 84 minutes (IC à $95 \%$, de 42 à $126 \mathrm{~min}$ ). Avant la mise en œuvre du protocole, $47 \%$ des patients ont reçu une couverture antibiotique appropriée pour la source présumée de l'infection, conformément aux lignes directrices locales publiées. Après la mise en œuvre du protocole, $73 \%$ des patients ont reçu initialement une antibiothérapie appropriée, ce qui représente une amélioration globale de $26 \%$.

Conclusion : Un protocole de prise en charge des états septiques à l'urgence fondé sur les lignes directrices pour l'évaluation et la prise en charge des patients en sepsis semble entraîner une amélioration du délai d'administration d'antibiotiques ainsi que de la pertinence de l'antibiothérapie initiale chez les patients en sepsis sévère.

From the *Department of Emergency Medicine, Calgary Health Region, Calgary, Alta., the †Departments of Family Medicine and Community Health Sciences, Faculty of Medicine, University of Calgary, Calgary, Alta., and the ¥Division of Emergency Medicine, London Health Sciences Centre, London, Ont.

Submitted Jan. 15, 2009; Revised May 31, 2009; Accepted Jun. 15, 2009

This article has been peer reviewed.

CJEM 2010;12(4):303-10 


\section{INTRODUCTION}

Severe sepsis and septic shock are common presentations in the emergency department (ED). In North America, these 2 entities account for $2.9 \%$ and $10 \%$ of total hospital and intensive care unit (ICU) admissions, respectively. ${ }^{1}$ In one Canadian study, $32 \%$ of patients with severe sepsis and septic shock seen in the ICU were initially admitted through the ED. ${ }^{2}$ Despite advances in medical therapy during the last 3 decades, the mortality rate for severe sepsis and septic shock remains very high, exceeding 30\% in some studies. ${ }^{3}$ Delays in the identification and early aggressive resuscitation of patients with severe sepsis and septic shock have been associated with higher mortality rates. ${ }^{4}$

Sepsis is defined by the presence of 2 or more systemic inflammatory response syndrome (SIRS) criteria in the setting of a presumed or documented infection. Severe sepsis is hallmarked by concomitant organ hypoperfusion or organ dysfunction. Septic shock results when systolic blood pressure falls below $90 \mathrm{~mm} \mathrm{Hg}$ or the mean arterial pressure falls below $65 \mathrm{~mm} \mathrm{Hg}$ despite adequate fluid resuscitation, and the patient requires vasopressor support. ${ }^{1}$

In 2003, critical care and infectious disease experts from 11 international organizations developed management guidelines for severe sepsis and septic shock. ${ }^{5}$ The Surviving Sepsis Campaign aimed to reduce sepsis mortality by $25 \%$ by the year $2009 .{ }^{6}$ Key recommendations of the guidelines include early recognition of sepsis, goal-directed resuscitation of the septic patient during the first 6 hours after recognition, and administration of broad-spectrum antibiotic therapy within the first hour of recognition. ${ }^{5}$ Failure to initiate prompt antibiotic therapy that is active against the causative pathogen has adverse consequences on patient outcome. ${ }^{7-10}$ The latest revision of the guidelines of the Surviving Sepsis Campaign in 2008 recommends intravenous antibiotic therapy be started as early as possible and within 1 hour of recognition of septic shock and severe sepsis without septic shock. ${ }^{11}$ This recommendation is echoed in recently published guidelines for optimal management of severe sepsis in Canadian EDs. ${ }^{12}$

To improve the recognition and care of septic patients in EDs within the Calgary Health Region, an ED sepsis protocol was developed. The aim of this protocol was to rapidly identify septic patients, institute early and aggressive resuscitation and reduce the overall time to antibiotics in patients with severe sepsis. We used an observational study design to assess the effects of our interventions on time to antibiotics in severe sepsis.

\section{METHODS}

\section{Quality improvement initiative}

The ED sepsis protocol of the Calgary Health Region was a paper-based protocol developed by a quality improvement committee, based on perceived need within the institution. This process was driven by the hospital administration, and the protocol was developed by representatives from emergency medicine and intensive care. It was not formally approved by all ED staff, and use by ED physicians was not mandatory. The protocol package consisted of a variety of components. For example, the protocol contained an early recognition patient screening tool for sepsis, as well as preprinted patient care order sets with appropriate diagnostic and therapeutic interventions (Appendix 1, available at www.cjem-online.ca) including intravenous antibiotic recommendations based on source of suspected sepsis (Box 1). The screening tool

Box 1. Initial empiric antibiotic guidelines for sepsis within the Calgary Health Region

Community-acquired pneumonia

- Ceftriaxone 2 g IV + azithromycin 500 mg IV

- Levofloxacin $500 \mathrm{mg}$ orally or IV

Intra-abdominal

- Piperacillin-tazobactam $3.375 \mathrm{~g} \mathrm{IV}$

- Ceftriaxone 2 g IV + metronidazole 500 mg IV

- Ampicillin $2 \mathrm{~g} \mathrm{IV} \mathrm{+} \mathrm{gentamicin} 6 \mathrm{mg} / \mathrm{kg} \mathrm{IV} \mathrm{+}$ metronidazole $500 \mathrm{mg} \mathrm{IV}$

Urosepsis

- Gentamicin $6 \mathrm{mg} / \mathrm{kg}$ IV

- Ceftriaxone $2 \mathrm{~g} \mathrm{IV}$

Central nervous system

- Dexamethasone $10 \mathrm{mg}$ before antibiotics + ceftriaxone $2 \mathrm{~g} \mathrm{IV}+$ vancomycin $1 \mathrm{~g} \mathrm{IV}$

Skin/bone/joint

- Cefazolin 2 g IV

- Cloxacillin $1 \mathrm{~g} \mathrm{IV}$

Fasciitis

- Clindamycin $600 \mathrm{mg}$ IV + penicillin G 4 million units IV Endocarditis

- Ceftriaxone $2 \mathrm{~g} \mathrm{IV}+$ vancomycin $1 \mathrm{~g}$ IV if MRSA is suspected

Infected central line

- Vancomycin $1 \mathrm{~g} \mathrm{IV}+$ pull the line

Neutropenia

- Piperacillin-tazobactam $3.375 \mathrm{~g} \mathrm{IV} \mathrm{+} \mathrm{gentamicin} 6$ mg/kg IV

Sepsis source unknown

- Treat as per intra-abdominal sepsis

IV = intravenously; MRSA = methicillin-resistant Staphylococcus aureus. 
could be activated at any point during the patient's visit to the ED including on first presentation to triage. Implementation of the protocol included educational rounds sessions to both nursing staff and physicians on proper use of the protocol as well as a general review of sepsis and management of the septic patient.

As part of the development of the paper-based sepsis protocol initial empiric antibiotic selection guidelines were developed in our health region in conjunction with infectious disease consultants. Recommendations were based on the presumed source of infection at initiation of therapy. First- and second-line antibiotic combinations were felt to have adequate activity against the likely pathogens and were guided by the susceptibility patterns of microorganisms in the local community and hospitals (Box 1).

\section{Study design and setting}

The protocol was implemented in April 2006 in urban EDs at 3 teaching hospitals with a combined annual census of 207000 visits. We retrospectively collected data on patients aged 18 years or older who met criteria for severe sepsis in the ED.

\section{Study participants}

We obtained institutional review board approval for review of patient charts for this study. From Oct. 1 to Dec. 31, 2004, ED encounters with International Classification of Diseases (ICD) codes related to infections were screened before the implementation of the sepsis protocol at all 3 ED sites (2004 sample). A wide variety of ICD-10 codes were used to identify possible patients with severe sepsis. The main codes included the following: sepsis, septicemia, urosepsis, septic shock and toxic shock. Data abstractors reviewed all these charts for sepsis and severe sepsis criteria.

From Oct. 1 to Dec. 31, 2006, ED encounters with the same ICD codes as above were screened during a similar period after implementation of the sepsis protocol at all 3 ED sites (2006 sample).

\section{Data abstraction}

Data abstraction was performed by trained medical residents and professional research nurses. Abstractors were blinded to the study hypothesis. Standardized data abstraction forms were used, and a preliminary sample of 50 charts were extracted by all abstractors to ensure uniformity. Periodic meetings and monitoring of performance was undertaken by the primary investigator.

Following initial identification, each potential chart was screened to determine whether the case met specific criteria for SIRS. All potential sources of documentation in the medical record were used, including triage vitals, nursing notes, timed laboratory reports and physician charting. Those cases not meeting at least 2 nonsimultaneous SIRS criteria were excluded from further analysis (Fig. 1). The remaining charts meeting criteria for SIRS were then assessed for specific criteria for severe sepsis and septic shock (Table 1) as described by the 1991 Society of Critical Care Medicine/American College of Chest Physicians Consensus Statement on Sepsis Definitions. ${ }^{13}$ Patients meeting criteria for severe sepsis made up the study sample and had the following data extracted: demographic information, triage time, bed assignment time, physician to bedside time, time that criteria for severe sepsis were met, time of initiation of antibiotics, initial SIRS and severe sepsis criteria that were met, initial choice of empiric antibiotic based on presumed source of infection, and the emergency physician's diagnosis.

\section{Empiric antibiotic selection}

Recording the initial empiric antibiotic coverage based

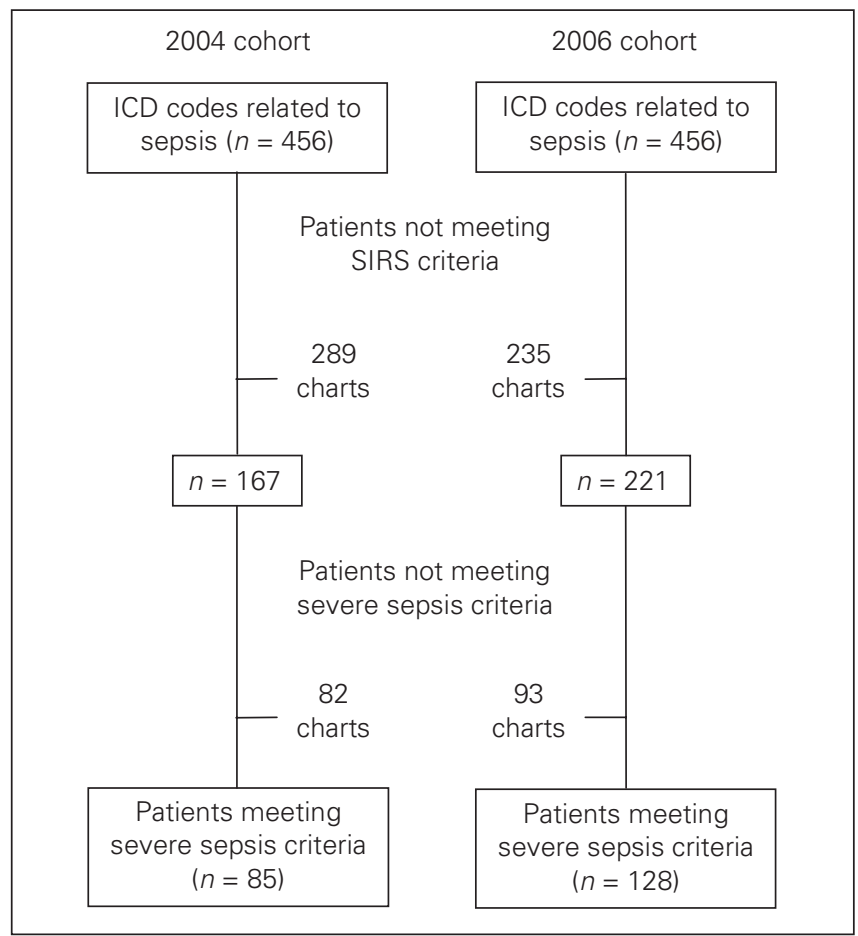

Fig. 1. Flow diagram for review of patient charts. ICD = International Classification of Diseases; SIRS = systemic inflammatory response syndrome. 
on the presumed source of infection and any patient allergies allowed us to assess the suitability of antibiotic selection. We compared the compliance rates with the locally published guidelines for empiric therapy before and after the implementation of the sepsis protocol (Box 1). Appropriate therapy was defined as receipt of any combination of the recommended antibiotics (even if additional antibiotics were received). Partially appropriate therapy was defined as the receipt of only one of a recommended combination of antibiotics, and inappropriate therapy was defined as not having received any of the recommended antibiotics.

Table 1. Characteristics of patients who met criteria for both the systemic inflammatory response syndrome and severe sepsis, before and after implementation of sepsis protocols

\begin{tabular}{|c|c|c|c|}
\hline \multirow[b]{2}{*}{ Characteristic } & \multicolumn{2}{|c|}{ No. $(\%)$ of patients* } & \multirow[b]{2}{*}{$p$ value } \\
\hline & Before implementation, $n=85^{*}$ & After implementation, $n=128^{*}$ & \\
\hline Mean (SD) age, yr & $66.4(17.3)$ & $62.6(17.9) \dagger$ & 0.13 \\
\hline Male sex & 49 (57.6) & 69 (53.9) & 0.64 \\
\hline Admitting ED & & & $<0.001$ \\
\hline Hospital A & 33 (38.8) & 50 (39.1) & \\
\hline Hospital B & 13 (15.3) & $50(39.1)$ & \\
\hline Hospital C & 39 (45.9) & $28(21.8)$ & \\
\hline \multicolumn{4}{|l|}{ Presumed etiology } \\
\hline Community-acquired pneumonia & $21 \quad(25.0) \ddagger$ & $41(32.3) \dagger$ & 0.26 \\
\hline Intra-abdominal & $18(21.4) \ddagger$ & $17(13.4) \dagger$ & 0.12 \\
\hline Urosepsis & $17(20.2) \ddagger$ & $16(12.6) \dagger$ & 0.13 \\
\hline Meningitis & $1 \quad(1.2) \ddagger$ & $\begin{array}{ll}0 & (0.0) \dagger\end{array}$ & 0.22 \\
\hline Cellulitis & $3 \quad(3.6) \neq$ & $13(10.2) \dagger$ & 0.07 \\
\hline Fasciitis & $(0.0) \ddagger$ & $1 \quad(0.8) \dagger$ & 0.42 \\
\hline Neutropenia & $0 \quad(0.0) \ddagger$ & $\begin{array}{ll}0 & (0.0) \dagger\end{array}$ & \\
\hline Other & 13 (15.5)‡ & $17(13.4) \dagger$ & 0.67 \\
\hline Unknown & $11(13.1) \ddagger$ & $22(17.3) \dagger$ & 0.41 \\
\hline Disposition & & & 0.57 \\
\hline Admitted & 78 (91.8) & $110(85.9)$ & \\
\hline Discharged & $4 \quad(4.7)$ & $9 \quad(7.0)$ & \\
\hline Died in ED & $3 \quad(3.5)$ & $8 \quad(6.3)$ & \\
\hline \multicolumn{4}{|l|}{ SIRS criteria met } \\
\hline Hyperthermia $\left(>38^{\circ} \mathrm{C}\right)$ & 49 (58.3) & $56(43.7)$ & 0.05 \\
\hline Hypothermia $\left(<36^{\circ} \mathrm{C}\right)$ & $9(10.7)$ & $13(10.2)$ & 0.92 \\
\hline Tachycardia (HR > 90 beats/min) & 69 (81.1) & 102 (79.7) & 0.80 \\
\hline Tachypnea (RR > 20 breaths/min) & 43 (50.6) & 81 (63.3) & 0.07 \\
\hline Glasgow Coma Scale score $<15$ & 26 (30.6) & $20(15.6)$ & 0.01 \\
\hline WBC count $>12 \times 10^{9} / \mathrm{L}$ & 49 (57.6) & $64(50.0)$ & 0.27 \\
\hline WBC count $<4 \times 10^{9} / \mathrm{L}$ & $3 \quad(3.5)$ & $7 \quad(5.5)$ & 0.51 \\
\hline WBC bands $>0 \times 10^{9} / \mathrm{L}$ & $5 \quad(5.9)$ & $4 \quad(3.1)$ & 0.33 \\
\hline \multicolumn{4}{|l|}{ Severe sepsis criteria met } \\
\hline Oxygen saturation < 90\% room air & $38(44.7)$ & $53(41.4)$ & 0.63 \\
\hline $\mathrm{SBP}<90 \mathrm{~mm} \mathrm{Hg}$ or MAP $<65 \mathrm{~mm} \mathrm{Hg}$ & 56 (65.9) & 87 (68.0) & 0.75 \\
\hline Oliguria $<0.5 \mathrm{~mL} / \mathrm{kg} / \mathrm{h}$ & $6 \quad(7.1)$ & $10 \quad(7.8)$ & 0.84 \\
\hline Creatinine $>60 \mu \mathrm{mol} / \mathrm{L}$ from baseline & $23(27.1)$ & $29(22.7)$ & 0.46 \\
\hline INR $>1.5 \mathrm{~s}$ or $\mathrm{PTT}>60 \mathrm{~s}$ & $12(14.1)$ & $10 \quad(7.8)$ & 0.14 \\
\hline Mottled & $9(10.6)$ & $10 \quad(7.8)$ & 0.49 \\
\hline Platelets $<100 \times 10^{9} / \mathrm{L}$ & $4 \quad(4.7)$ & $13(10.2)$ & 0.15 \\
\hline Bilirubin > $70 \mathrm{mmol} / \mathrm{L}$ & $5 \quad(5.9)$ & $5 \quad$ (3.9) & 0.50 \\
\hline Lactate $>4 \mathrm{mmol} / \mathrm{L}$ & $18(21.2)$ & 26 (20.3) & 0.88 \\
\hline $\begin{array}{l}\text { ED = emergency department; } \mathrm{HR}=\text { heart rate; } I N R=\text { inte } \\
\mathrm{SBP}=\text { systolic blood pressure; } \mathrm{SD}=\text { standard deviation; } \\
\text { *Unless otherwise indicated. } \\
+n=127 \text {; this information was missing from } 1 \text { chart. } \\
\neq n=84 ; \text { this information was missing from } 1 \text { chart. }\end{array}$ & $\begin{array}{l}\text { tional normalized ratio; } \mathrm{MAP}=\text { mean arteria } \\
S=\text { systemic inflammatory response syndrc }\end{array}$ & $\begin{array}{l}; \text { PTT = partial thromboplastin time; } R R=r \\
=\text { white blood cell. }\end{array}$ & \\
\hline
\end{tabular}




\section{Outcome measures}

Our primary outcome was the median time to antibiotic administration in the ED in patients meeting criteria for severe sepsis before and after the implementation of an ED sepsis protocol. Our secondary outcome was compliance with published Surviving Sepsis Campaign guidelines for time to antibiotics in severe sepsis, and appropriateness of initial empiric antibiotic therapy in severe sepsis based on locally published guidelines.

\section{Primary data analysis}

Statistical analysis was performed using the KaplanMeier survival analysis and the log-rank test for nonparametric data and was compared before and after implementation of the intervention. All outcome measures are given as point estimates with $95 \%$ confidence intervals (CIs) based on the method proposed by Bonett and Price. ${ }^{14}$ Reduction in median time is given as preimplementation time minus postimplementation time. Where indicated, median values are reported and all times are reported in minutes. Cox proportional hazard regression was used to investigate whether the time to antibiotics was confounded or modified by the ED. We considered $p \leq 0.05$ significant; no adjustments were made for multiple statistical tests. Intercooled STATA version 9.2 (SPSS Inc.) was used for all statistical analyses.

\section{RESULTS}

In total, 912 charts were reviewed in the 2 combined cohorts. Of these, 213 met our diagnostic criteria for severe sepsis. Of the patients included in the 2004 review, 85 patients met the criteria for severe sepsis. In the 2006 review, 128 patients met the criteria (Fig. 1). The characteristics of patients included in the analysis are shown in Table 1 . The 2 cohorts were similar in terms of demographics, sources of infection and number of patients meeting both SIRS and severe sepsis criteria.

\section{Demographic and descriptive data}

The median age of severe sepsis patients was 64.1 years. There was approximately equal representation from all 3 ED sites within the health region. Of the 213 patients, $188(89 \%)$ were admitted to hospital, 11 (5\%) died in the ED and 13 (6\%) were discharged home with outpatient follow-up for intravenous antibiotics. One patient in the postimplementation group was lost to disposition follow-up. The most common infectious etiologies for severe sepsis were community-acquired pneumonia (29\%), intra-abdominal sepsis (17\%) and urosepsis (16\%); $21 \%$ of patients had an unknown source of sepsis at the time of ED departure. The most common SIRS criteria that were met by the patients with severe sepsis were tachycardia (heart rate $>90$ beats $/ \mathrm{min}$ ), tachypnea (respiratory rate $>20$ breaths/min) and leukocytosis (white blood count $>12 \times 10^{9} / \mathrm{L}$ ) in $80 \%, 64 \%$ and $50 \%$, respectively. The most common criteria met for severe sepsis were hypotension (systolic blood pressure $<90 \mathrm{~mm} \mathrm{Hg}$ or mean arterial pressure $<65 \mathrm{~mm} \mathrm{Hg}$ ), hypoxia (oxygen saturation $<90 \%$ on room air) and renal insufficiency (creatinine $>60 \mu \mathrm{mol} / \mathrm{L}$ from baseline) in $69 \%, 42 \%$ and $23 \%$, respectively.

\section{Time to antibiotics in patients with severe sepsis}

We observed a statistically significant decrease in time to antibiotics from the time criteria for severe sepsis were met, after implementation of the ED sepsis protocol $(\log$-rank test $p$ value < 0.001) (Fig. 2). Comparisons of all median time intervals between the pre- and postimplementation cohorts are shown in Table 2. Before implementation of the protocol, the median time from the time criteria for severe sepsis were met to antibiotic delivery was 163 minutes (95\% CI 124 to $210 \mathrm{~min}$ ). Implementation of the ED sepsis protocol resulted in a median time from the time criteria for severe sepsis were met to antibiotic delivery of 79 minutes (95\% CI 64 to $94 \mathrm{~min})$.

We observed reductions in all median times to antibiotic delivery (Table 2); however, some reductions were

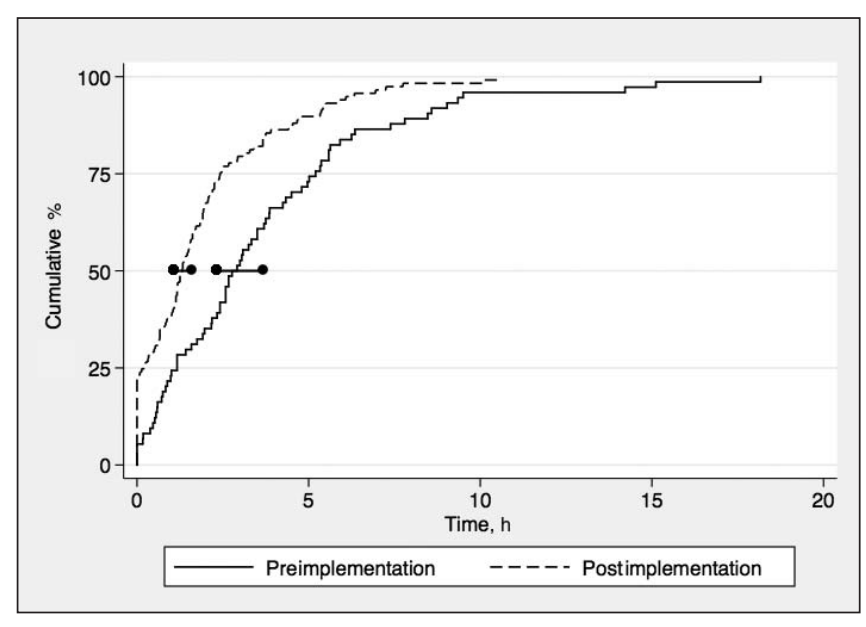

Fig. 2. Time to antibiotics from the time severe sepsis criteria were met, before and after implementation of the sepsis protocol. 
not statistically significant. For example, triage to antibiotic delivery (28 $\mathrm{min}$; $95 \% \mathrm{CI}-38$ to $92 \mathrm{~min}$ ) and bed assignment to antibiotic delivery (52 $\mathrm{min}$; $95 \% \mathrm{CI}-2$ to $105 \mathrm{~min}$ ) were not significantly reduced. The time from severe sepsis criteria being met to antibiotic delivery was significantly reduced ( $84 \mathrm{~min}$; $95 \%$ CI 42 to $126 \mathrm{~min}$ ). Patients receiving antibiotics within 1 hour of recognition of severe sepsis as outlined by the Surviving Sepsis Campaign guidelines increased from $24.3 \%$ (95\% CI $14.5 \%$ to $34.1 \%$ ) in 2004 to $38.5 \%$ (95\% CI $29.6 \%$ to $47.3 \%)$ in $2006(p=0.043)$.

There was a statistically significant difference in the ED distribution of the patients between the 2 samples with a greater percentage of patients seen at hospital C in the preimplementation sample. Cox proportional hazards regression was used to investigate whether the time to antibiotics was confounded or modified by ED visited. Indicator values were generated for each ED and modification was assessed via likelihood ratio test of the interaction terms between exposure (implementation) and hospital (likelihood ratio $\chi^{2}=0.23 ; d f=2 ; p=$ $0.89)$. Confounding was assessed by considering the model with and without adjustment for hospital and determining whether there was a meaningful change in the hazard ratio. Hospital site was not shown to modify or confound the results.

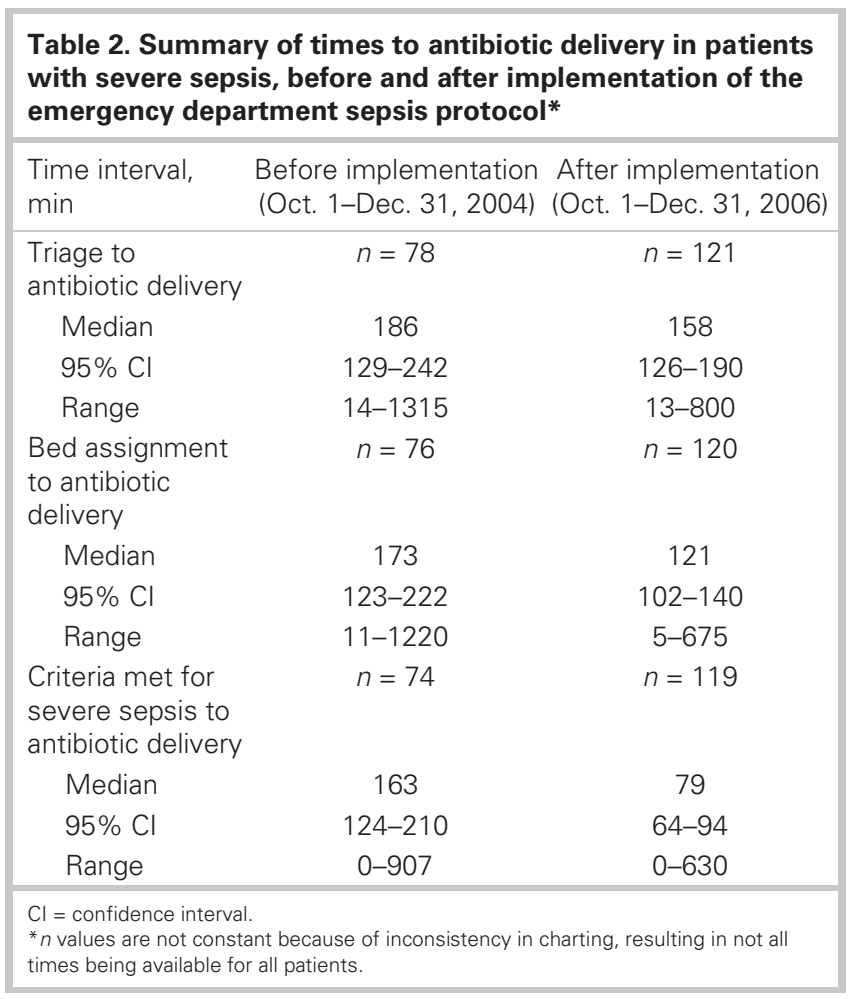

\section{Appropriateness of initial empiric antibiotic coverage}

In the preimplementation sample, all 85 patients meeting criteria for severe sepsis received antibiotics. Appropriate initial empiric antibiotics as outlined by local published guidelines were received in 40 (47\%) patients. Partially appropriate antibiotic coverage was administered in 28 (33\%) and inappropriate coverage in $19(22 \%)$. In the 2006 sample, antibiotics were not given in 3 patients meeting criteria for severe sepsis with no obvious explanation. In the remaining $125 \mathrm{pa}-$ tients, appropriate initial empiric antibiotic therapy was received in 91 (73\%) patients. Partially appropriate coverage was administered in $15(12 \%)$ and inappropriate coverage in $16(13 \%)$. This represented an overall improvement of $26 \%$ in the number of patients initially receiving appropriate antibiotics.

\section{DISCUSSION}

Management of the septic patient is no longer confined to the ICU. Recent advances in recognition and early management of severe sepsis and septic shock have focused on the critical first 24 hours of patient care that is often initiated in the ED. Early goal-directed therapy in the first 6 hours after presentation of severe sepsis has been shown to significantly improve mortality with a number needed to treat of 6 patients to prevent 1 death. ${ }^{15}$ We found that the introduction of a quality improvement initiative designed to increase recognition of the clinical features of SIRS and severe sepsis resulted in earlier administration of appropriate antibiotic therapy.

Although antibiotic therapy is the cornerstone in the treatment of infections, it is only recently that the association of timely and appropriate antibiotic therapy has been shown to improve morbidity and mortality in severe sepsis and septic shock. ${ }^{16-19}$ Observational studies have shown a significant reduction in mortality when antibiotics are administered within the first 4 to 8 hours of hospital presentation..$^{16,17}$ Kumar and colleagues ${ }^{18}$ showed that in patients with recurrent or persistent septic shock, each hour of delay in initiation of effective antimicrobial therapy during the first 6 hours of presentation was associated with a mean decrease in survival of $7.5 \%$ (95\% CI $3.6 \%$ to $9.9 \%)$. In further multivariate analysis, it was demonstrated that time to effective antimicrobial therapy in septic shock had the strongest association with outcome. ${ }^{18}$ Garnacho-Montero and coauthors ${ }^{19}$ showed that in patients admitted to the ICU with severe sepsis and septic shock, the risk of in-hospital mortality was 8 times 
greater in patients receiving inadequate antimicrobial therapy within the first 24 hours, compared with those receiving adequate empiric antibiotic therapy.

It is our opinion that the delays seen in initiation of antibiotics in severe sepsis and septic shock are often a product of poor early recognition. The time to antibiotic therapy can be used as a surrogate marker of early recognition and prompt management of this patient group. In an effort to streamline the recognition and management of these patients, we devised a sepsis protocol that included a patient screening tool that could be activated at triage or at the bedside, as well as a data order set including recommended initial empiric antibiotics based on suspected source of infection.

The implementation of our ED sepsis protocol appears to have significantly decreased the time from criteria for severe sepsis being met to antibiotic administration. With a statistically and clinically significant improvement in time to antibiotics in severe sepsis, an ED-based protocol has the potential to markedly improve morbidity and mortality in this patient population presenting to the ED. It is interesting to note that although the protocol had a significant improvement on the time severe sepsis criteria were met to time of antibiotic administration, there were less significant gains made in time from bed assignment to time of antibiotic administration and a statistically nonsignificant gain of only 28 minutes from triage time to time of antibiotic administration. These findings would seem to indicate that most of the significant gains in time to antibiotics administration occurred after the patients were in the ED. We were optimistic that the ED sepsis protocol initiated at triage would aid in earlier identification of these patients at the moment of their arrival into the system. Further review of our data set revealed that in the combined cohorts, $47 \%$ of the patients met criteria for severe sepsis within 30 minutes of their triage time. The remaining $53 \%$ of patients met sepsis criteria at varying times within their stay in the ED. This statistic alone likely accounts for the relative lack of gains in time from triage to antibiotic delivery. Early activation of the sepsis protocol at triage in this patient population would still have the potential to aid in early recognition of these patients should their conditions deteriorate while awaiting investigations or workup in the ED.

\section{Limitations and future questions}

Our study has a number of limitations. The study design was a retrospective chart review with potential for bias and unrecorded confounders. Because patients were identified initially by ICD codes, there is a possibility that patients with severe sepsis could have been missed. We believe that our screening ICD codes were broad enough to identify most potential patients at risk for severe sepsis. The study was also limited by the quality of ED charting, and there was the potential for inconsistencies in documented times. Attempts were made to use times that were consistently documented in the charts, such as triage time, bed assignment time and time of antibiotics administration, to improve data collection accuracy. We did not compare the ED census and staffing between the periods before and after implementation of the study, although we used the same 3-month study period separated by 2 years.

The retrospective nature of the study design makes it intrinsically difficult to establish causality between the results obtained and the implementation of our sepsis protocol. A specific review of ED practices between the selected periods revealed no specific changes in triage process, charting practices, diagnostics, patient monitoring or quality assurance. Implementation of the protocol did, however, result in antimicrobial ward stock changes at 2 of the hospital sites. Hospitals A and C both added piperacillin-tazobactam and vancomycin as ward stock, whereas Hospital B already had all antibiotics in the ED. Specific statistical analysis was undertaken and demonstrated that the ED attended did not modify or confound the results, making pharmacy distribution changes unlikely to have played a significant role.

Our definition of severe sepsis could be questioned. Patients in our study were determined to have met the criteria for severe sepsis once they demonstrated any time-documented finding consistent with severe sepsis (Table 1). Hypotension (defined as any single reading of systolic blood pressure $<90 \mathrm{~mm} \mathrm{Hg}$ or mean arterial pressure $<65 \mathrm{~mm} \mathrm{Hg}$ ) was met in $69 \%$ of the patients with severe sepsis and hypoxia (oxygen saturation $<90 \%$ on room air) was met in a further $42 \%$ of these patients. Both of these criteria have the potential for inaccuracy in measurement. By the most widely accepted definition, septic shock requires hypotension persistent from onset despite adequate fluid (defined as $>20 \mathrm{~mL} / \mathrm{kg}$ of saline or equivalent) administration. ${ }^{13}$ It was impossible for us to assess fluid resuscitation within the limits of the charts that were reviewed, so any documented episode of hypotension was determined to have met criteria for severe sepsis.

We conducted multiple statistical tests, which inflates the overall chance for Type I errors; $p$ values approxi- 
mating 0.05 should be interpreted with caution. Our secondary outcome looking at appropriateness of antibiotic therapy allowed for a limited choice of antibiotics that were considered acceptable by our definition. Although allowances were made for patient allergies, our definition of appropriate antibiotic therapy left little room for clinical judgment or antimicrobial selection outside of the locally published guidelines. It is entirely possible that comparable and equally effective antibiotics may have been selected based on patient factors or known pathogens from prior cultures. The improved compliance with the guidelines postimplementation of the protocol indicates that it was effective in steering antimicrobial selection and does demonstrate the potential for improved patient care.

We did not study patient outcome or perform a cost analysis. The possibility of a morbidity and mortality benefit from the protocol can only be presumed based on the understanding that prior investigations have demonstrated that, in septic shock, every hour of delay in initiation of appropriate antibiotics is associated with a $12 \%$ decrease in the probability of survival ${ }^{16}$ and, in severe sepsis and septic shock, the risk of in-hospital death is 8 times greater in patients receiving inadequate antimicrobial therapy within the first 24 hours. ${ }^{17}$ In the clinical environment of a busy ED, the time savings involved in our protocol could also positively impact ED flow and expedite patient care.

Future research should be directed toward a mortality analysis and a longer length of data collection to determine if the benefits of the sepsis protocol are retained or subject to deterioration with time. A randomized clinical trial comparing an ED-based sepsis protocol to nonprotocol driven sepsis management at 2 similar ED sites would be a logical next step.

\section{CONCLUSION}

A guideline-based ED sepsis protocol for the evaluation and treatment of the septic patient appears to improve the time to administration of antibiotics as well as the appropriateness of initial antibiotic therapy in the subset of patients with severe sepsis. Further research is warranted to examine other reasons and solutions for these delays.

Competing interests: None declared.

\section{REFERENCES}

1. Rivers EP, McIntyre L, Morro DC, et al. Early and innovative interventions for severe sepsis and septic shock: taking advan- tage of a window of opportunity. CMAJ 2005;173:1054-65.

2. McIntyre LA FD, Herbert PC, Cook DJ, et al. Are delays in the recognition and initial management of patients with severe sepsis associated with hospital mortality? Crit Care Med 2003;31[12(suppl)]:A75.

3. Angus DC, Linde-Zwirble WT, Lidicker J, et al. Epidemiology of severe sepsis in the United States: analysis of incidence, outcome, and associated costs of care. Crit Care Med 2001;29:1303-10.

4. Lundberg JS, Perl TM, Wiblin T, et al. Septic shock: an analysis of outcomes for patients with onset on hospital wards versus intensive care units. Crit Care Med 1998;26:1020-4.

5. Dellinger RP, Carlet JM, Masur H, et al. Surviving Sepsis Campaign guidelines for management of severe sepsis and septic shock. Crit Care Med 2004;32:858-73.

6. Dellinger RP, Carlet JM, Masur H, et al. Surviving Sepsis Campaign guidelines for management of severe sepsis and septic shock. Intensive Care Med 2004;30:536-55.

7. McCabe WR, Jackson GG. Gram negative bacteremia. Arch Intern Med 1962;110:847-55.

8. Leibovici L, Shraga I, Drucker M, et al. The benefit of appropriate empirical antibiotic treatment in patients with bloodstream infection. J Intern Med 1998;244:379-86.

9. Ibrahim EH, Sherman G, Ward S, et al. The influence of inadequate antimicrobial treatment of bloodstream infections on patient outcome in the ICU setting. Chest 2000;118:146-55.

10. Bochud PY, Bonten M, Marchetti O, et al. Antimicrobial therapy for patients with severe sepsis and septic shock: an evidence-based review. Crit Care Med 2004;32(suppl):S495-512.

11. Dellinger RP, Levy MM, Carlet JM, et al. Surviving Sepsis Campaign: international guidelines for management of severe sepsis and septic shock: 2008. Crit Care Med 2008;36:296-327.

12. Green RS, Djogovic D, Gray S, et al. Canadian Association of Emergency Physicians Sepsis Guidelines: the optimal management of severe sepsis in Canadian emergency departments. CJEM 2008;10:443-59.

13. Bone RC, Balk R, Cerra FB, et al. ACCP/SCCM consensus conference: definitions for sepsis and organ failure and guidelines for use of innovative therapies in sepsis. Chest 1992;101:1644-55.

14. Bonett DG, Price RM. Statistical inference for a linear function of medians: confidence intervals, hypothesis testing and sample size requirements. Psychol Methods 2002;7:370-83.

15. Rivers E, Nguyen B, Havstad S, et al. Early goal-directed therapy in the treatment of severe sepsis and septic shock. N Engl J Med 2001;345:1368-77.

16. Houck PM, Bratzler DW, Nsa W, et al. Timing of antibiotic administration and outcomes for medicare patients hospitalized with community-acquired pneumonia. Arch Intern Med 2004;164:637-44.

17. Meehan TP, Fine JM, Krumholz HM, et al. Quality of care, process and outcomes in elderly patients with pneumonia. JAMA 1997;278:2080-4.

18. Kumar A, Roberts D, Wood KE, et al. Duration of hypotension before initiation of effective antimicrobial therapy is the critical determinant of survival in human septic shock. Crit Care Med 2006;34:1589-96.

19. Garnacho-Montero J, Garcia-Garmendia JL, BarreroAlmodovar A, et al. Impact of adequate empirical antibiotic therapy on the outcome of patients admitted to the intensive care unit with sepsis. Crit Care Med 2003;31:2742-51.

Correspondence to: Dr. Marc Francis, Department of Emergency Medicine, Foothills Medical Centre, Rm. C231, 1403-29th St. NW, Calgary AB T2N 2T9; marc.francis@calgaryhealthregion.ca 


\section{calgary health region}

\section{EMERGENCYIURGENT CARE}

UNIT MANUAL

\begin{tabular}{|l|l|l|l|}
\hline $\begin{array}{l}\text { Subject/Title: } \\
\text { Suspected Se ptic Patient Protoc ol ( } \geq \mathbf{1 4} \text { years of } \\
\text { age) }\end{array}$ & $\begin{array}{l}\text { Reference Number: } \\
\text { S-4 }\end{array}$ \\
\hline $\begin{array}{l}\text { Authorization: } \\
\text { Director of Emergency \& Urgent Care Services }\end{array}$ & $\begin{array}{l}\text { Date } \\
\text { Established } \\
2006.05\end{array}$ & $\begin{array}{l}\text { Date } \\
\text { Reviewed: } \\
2007.08\end{array}$ \\
Regional Clinical Department Head for Emergency Medicine & & \\
Medical Director Urgent Care Services & & \\
\hline $\begin{array}{l}\text { Classification: } \\
\text { Protocol }\end{array}$ & Page: 1 OF 11 \\
\hline
\end{tabular}

\section{PURPOSE}

CHR Emergency/Urgent Care Unit Protocols are designed to provide health care providers with designated protocols to initiate specific diagnostics, therapeutics and interventions for patients, prior to initial physician assessment. This protocol is intended for those patients who have a known or suspected infection and two or more S.I.R.S criteria on the Suspected Septic Patient Triage and Bedside Screening Tools. (Appendix I \& II)

\section{PERSONNEL PERMITTED TO PERFORM PROTOCOL}

Registered Nurse

\section{PROTOCOL}

A complete nursing assessment including a full set of vital signs ( $T, P, B P, R R$ and $\mathrm{O} 2$ saturation) must be obtained. Immediately notify the Nurse Clinician and the Emergency/Urgent Care Physician of any patient who presents with suspected Sepsis and or signs and symptoms of shock.

1. Administer oxygen up to $5 \mathrm{~L}$ via nasal prongs or $10-12 \mathrm{~L}$ via non-rebreather mask. Page Respiratory Therapy to assist with airway management as required.

2. Apply cardiac monitor leads; monitor the patient in lead II and V1. Interpret the rhythm strip and place on patient care record. If patient triaged to a non-monitored bed, place patient on portable monitor.

3. Start 2 IV's with as large a bore cannula as possible. Attach double or triple extension sets. Infuse Normal Saline at TKVO pending further orders from the Emergency/Urgent Care Physician.

4. Perform a 12 lead ECG and bring to the physician immediately if there are any abnormalities present.

5. Specimen Collection for:

I. $\mathrm{CBC}$, Electrolyte panel $(\mathrm{Na}, \mathrm{K}, \mathrm{Cl}, \mathrm{CO} 2)$, glucose, creatinine. 


\begin{tabular}{|l|c|c|c|c|l||}
\hline $\begin{array}{l}\text { Subject/Title: } \\
\text { SUSPECTED SEPTIC PATIENT PROTOCOL } \\
14 \text { YEARS OF AGE) }\end{array}$ & $\begin{array}{l}\text { Date } \\
\text { Established } \\
2006.05\end{array}$ & $\begin{array}{l}\text { Date } \\
\text { Reviewed/ } \\
\text { Revised: } \\
2007.08\end{array}$ & $\begin{array}{l}\text { Referenc } \\
\text { e No.: } \\
\text { S-4 }\end{array}$ & $\begin{array}{l}\text { Page: } \\
2 \text { of } \\
11\end{array}$ \\
\hline
\end{tabular}

II. Draw and send extra tubes for coagulation and/or additional chemistry studies that may be ordered.

III. If temperature $\geq 38.5^{\circ} \mathrm{C}$, obtain 2 sets of blood cultures. Each set includes an aerobic and anaerobic bottle. The sets must be drawn from two different sites.

IV. Point of Care Test (POCT) urine dip - send to lab for urinalysis if any results positive.

5. Consider the following based on patient history and clinical presentation:

I. Orthostatic vital signs.

II. Urine culture - if urine dip results are positive for nitrites and or leukocytes.

III. Type and screen.

6. Document all blood work and/or diagnostics sent on the Emergency Chart, under Physician's Orders, write "Protocol Labs/Diagnostics Ordered", followed by your signature. Record on the Emergency Patient Treatment/Assessment Record as well.

7. Please refer to the following Appendices for further information regarding the management/care of the suspected septic patient:

I. Suspected Septic Patient Triage Screening Tool

II. Suspected Septic Patient Bedside Nurse Screening Tool

III. Physician Screening Tool for Severe Sepsis

IV. Severe Sepsis/Septic Shock Algorithm

V. Adult Severe Sepsis and Septic Shock Patient Care Orders

\section{REFERENCES}

Rady, M.Y., Rivers, E. P., Nowak, R.M. (1996). Resuscitation of the critically ill in the ED: responses of blood pressure, heart rate, shock index, central venous oxygen saturation, and lactate. American Journal of Emergency Medicine, 14, 218-225.

Rivers, Emanual P., Mclntyre, L., Morro, D., \& Rivers, K. (2005). Early and innovative interventions for severe sepsis and septic shock: taking advantage of a window of opportunity. Canadian Medical Association Journal, 173 (9), 1054-1065.

Rivers, E., Nguyen, B., Havstad, S. Ressler, J., Muzzin, A, Knoblich, B. et al. (2001). Early goal-directed therapy in the treatment of severe sepsis and septic shock. New England Journal of Medicine, $\underline{345}, 1368-1377$.

\section{CROSS REFERENCES}

MANUAL: $\quad$ NUMBER: SUBJECTITITLE:

\section{DISCLAIMER}

All content in this policy and/or procedure is (c) copyright, Calgary Health Region. All rights reserved. This information, and as amended from time to time, was created expressly for use by Calgary Health Region staff and persons acting on behalf of the Calgary Health Region for 


\section{EMERGENCY/URGENT CARE \\ UNIT MANUAL}

\begin{tabular}{|l|l|l|l|l|l||}
\hline $\begin{array}{l}\text { Subject/Title: } \\
\text { SUSPECTED SEPTIC PATIENT PROTOCOL } \\
14 \text { YEARS OF AGE) }\end{array}$ & $\begin{array}{l}\text { Date } \\
\text { Established } \\
2006.05\end{array}$ & $\begin{array}{l}\text { Date } \\
\text { Reviewed/ } \\
\text { Revised: } \\
2007.08\end{array}$ & $\begin{array}{l}\text { Referenc } \\
\text { e No.: } \\
\text { S-4 }\end{array}$ & $\begin{array}{l}\text { Page: } \\
3 \text { of } \\
11\end{array}$ \\
\hline
\end{tabular}

guiding actions and decisions taken on behalf of the Calgary Health Region. The Calgary Health Region accepts no responsibility for any modification and/or redistribution and is not liable in any way for any actions taken by individuals based on the information herein, or for any inaccuracies, errors, or omissions in the information in this policy and/or procedure. Any modification and/or adoption of this policy and/or procedure are done so at the risk of the adopting organization. 
UNIT MANUAL

\begin{tabular}{|c|c|c|c|c|}
\hline $\begin{array}{l}\text { Subject/Title: } \\
\text { SUSPECTED SEPTIC PATIENT } \\
\quad \text { PROTOCOL ( } \geq 14 \text { YEARS OF AGE) }\end{array}$ & $\begin{array}{c}\text { Date } \\
\text { Established } \\
2006.05\end{array}$ & $\begin{array}{l}\text { Date } \\
\text { Reviewed/ } \\
\text { Revised: } \\
\quad 2007.08\end{array}$ & $\begin{array}{l}\text { Refere } \\
\text { nce } \\
\text { No.: } \\
\quad \text { S-4 }\end{array}$ & $\begin{array}{l}\text { Page: } \\
5 \text { of } \\
11\end{array}$ \\
\hline
\end{tabular}

\title{
SUSPECTED SEPTIC PATIENT BEDSIDE SCREENING TOOL
}

\author{
calgary health region
}

Department of Emergency Medicine

patient label

\section{Known or Suspected Infection}

Pneumonia, emphysema

$\square \quad$ Urinary tract infection

$\square$ Acute Abdominal infection

Meningitis

$\square$ Skin/soft tissue infection

Bone/joint infection

Wound infection

Infection from Catheter

Endocarditis

Implantable device infection

No known source other than clinical suspicion

Other

Severe pain associated with known or suspected source of infection

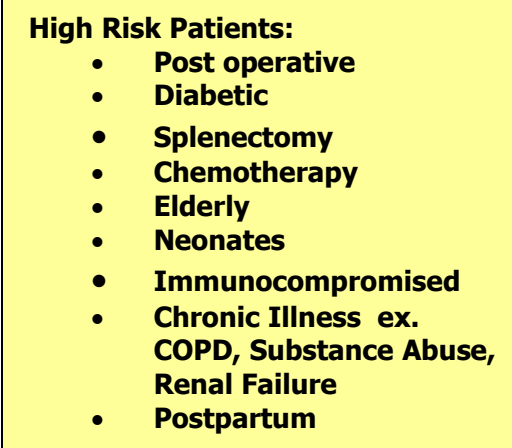

High Risk Patients:

- Post operative

- Diabetic

- Splenectomy

- Chemotherapy

- Elderly

- Neonates

- Immunocompromised

COPD, Substance Abuse,

al Failure

- Postpartum

\section{B. S.I.R.S. (Systemic Inflammatory Response Syndrome) criteria}

$\square \quad$ Hyperthermia $>38^{\circ} \mathrm{C}$

- Hypothermia $<36^{\circ} \mathrm{C}$

口 Tachycardia $>90 \mathrm{bpm}$

- Tachypnea $>20 \mathrm{rpm}$

$\square \quad$ Acutely altered mental status (GCS $<15)$ prior to sedation

- Leukocytosis (WBC count $>12.0 \times 10 \mathrm{E} / \mathrm{L})$

$\square$ Presence of any bands

\section{Primary RN: If patient has a Known or Suspected Infection from Section A, and $\geq 2$ S.I.R.S. criteria from Section B, then: \\ $\square$ Immediately notify charge nurse of patient. \\ $\square$ Confirm patient's priority number and if required, have it changed. Ensure patients are seen quickly \\ - Place Sepsis Package with patient's chart \\ - Refer Suspected Septic Patient Nursing Guideline on back of form}

At anytime through out a patient stay screening for suspected sepsis may occur. 


\section{EMERGENCY/URGENT CARE}

UNIT MANUAL

\begin{tabular}{|l|l|l|l|l||}
\hline $\begin{array}{l}\text { Subject/Title: } \\
\text { SUSPECTED SEPTIC PATIENT }\end{array}$ & $\begin{array}{l}\text { Date } \\
\text { Established }\end{array}$ & $\begin{array}{l}\text { Date } \\
\text { Reviewed/ } \\
\text { Revised: } \\
2007.08\end{array}$ & $\begin{array}{l}\text { Refere } \\
\text { nce } \\
\text { No.: } \\
\text { S-4 }\end{array}$ & $\begin{array}{l}\text { Page: } \\
6 \text { of } \\
11\end{array}$ \\
\hline
\end{tabular}

MD Notified at: 


\begin{tabular}{|c|c|c|c|c|}
\hline $\begin{array}{l}\text { Subject/Title: } \\
\text { SUSPECTED SEPTIC PATIENT } \\
\text { PROTOCOL ( } \geq 14 \text { YEARS OF AGE) }\end{array}$ & $\begin{array}{c}\text { Date } \\
\text { Established } \\
2006.05\end{array}$ & $\begin{array}{l}\text { Date } \\
\text { Reviewed/ } \\
\text { Revised: } \\
\quad 2007.08\end{array}$ & $\begin{array}{l}\text { Refere } \\
\text { nce } \\
\text { No.: } \\
\quad \text { S-4 }\end{array}$ & $\begin{array}{l}\text { Page: } \\
7 \text { of } \\
11\end{array}$ \\
\hline
\end{tabular}

\section{PHYSICIAN SCREENING TOOL fOr SEVERE SEPSIS Pilot Form- Please retain on patient chart}

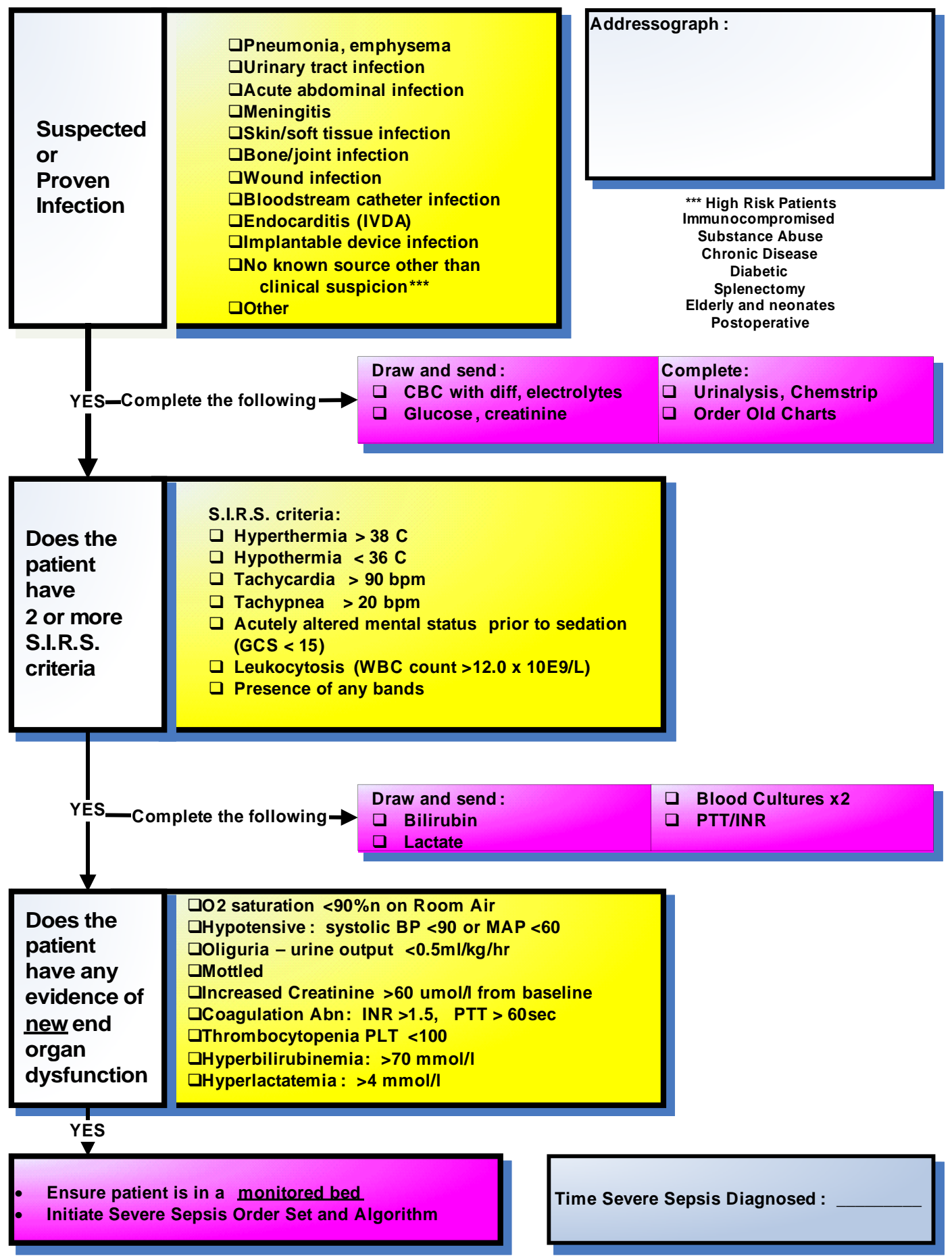




\begin{tabular}{|c|c|c|c|c|}
\hline $\begin{array}{l}\text { Subject/Title: } \\
\text { SUSPECTED SEPTIC PATIENT } \\
\text { PROTOCOL ( } \geq 14 \text { YEARS OF AGE) }\end{array}$ & $\begin{array}{c}\text { Date } \\
\text { Established } \\
2006.05\end{array}$ & $\begin{array}{l}\text { Date } \\
\text { Reviewed/ } \\
\text { Revised: } \\
\quad 2007.08\end{array}$ & $\begin{array}{l}\text { Refere } \\
\text { nce } \\
\text { No.: } \\
\quad \text { S-4 }\end{array}$ & $\begin{array}{l}\text { Page: } \\
8 \text { of } \\
11\end{array}$ \\
\hline
\end{tabular}

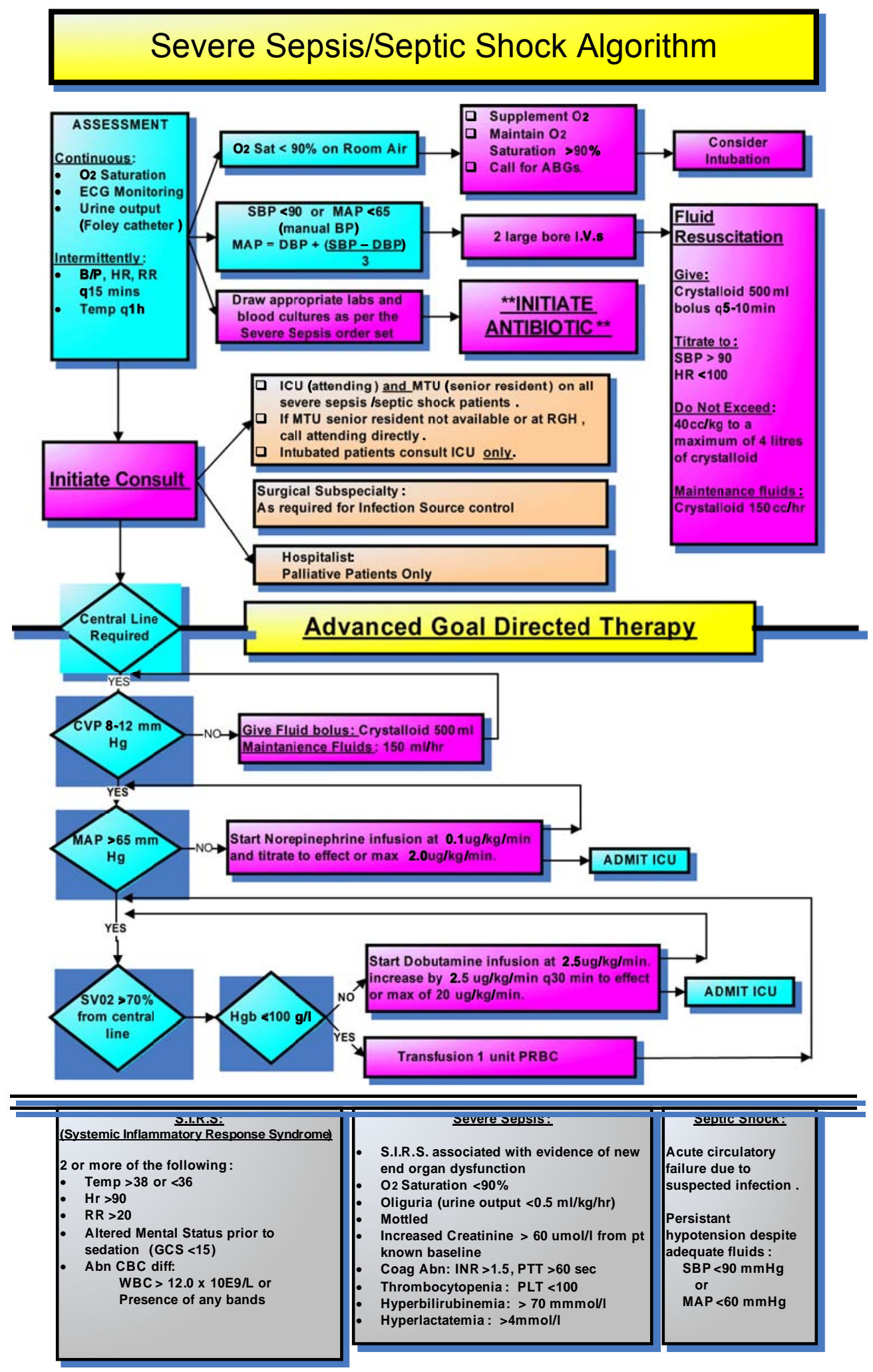

Emergency/Urgent Care Unit Manual 
UNIT MANUAL

\begin{tabular}{|l|l|l|l|l||}
\hline $\begin{array}{l}\text { Subject/Title: } \\
\text { SUSPECTED SEPTIC PATIENT }\end{array}$ & $\begin{array}{l}\text { Date } \\
\text { Established }\end{array}$ & $\begin{array}{l}\text { Date } \\
\text { Reviewed/ } \\
\text { Revised: } \\
2007.08\end{array}$ & $\begin{array}{l}\text { Refere } \\
\text { nce } \\
\text { No.: } \\
\text { S-4 }\end{array}$ & $\begin{array}{l}\text { Page: } \\
9 \text { of } \\
11\end{array}$ \\
\hline
\end{tabular}

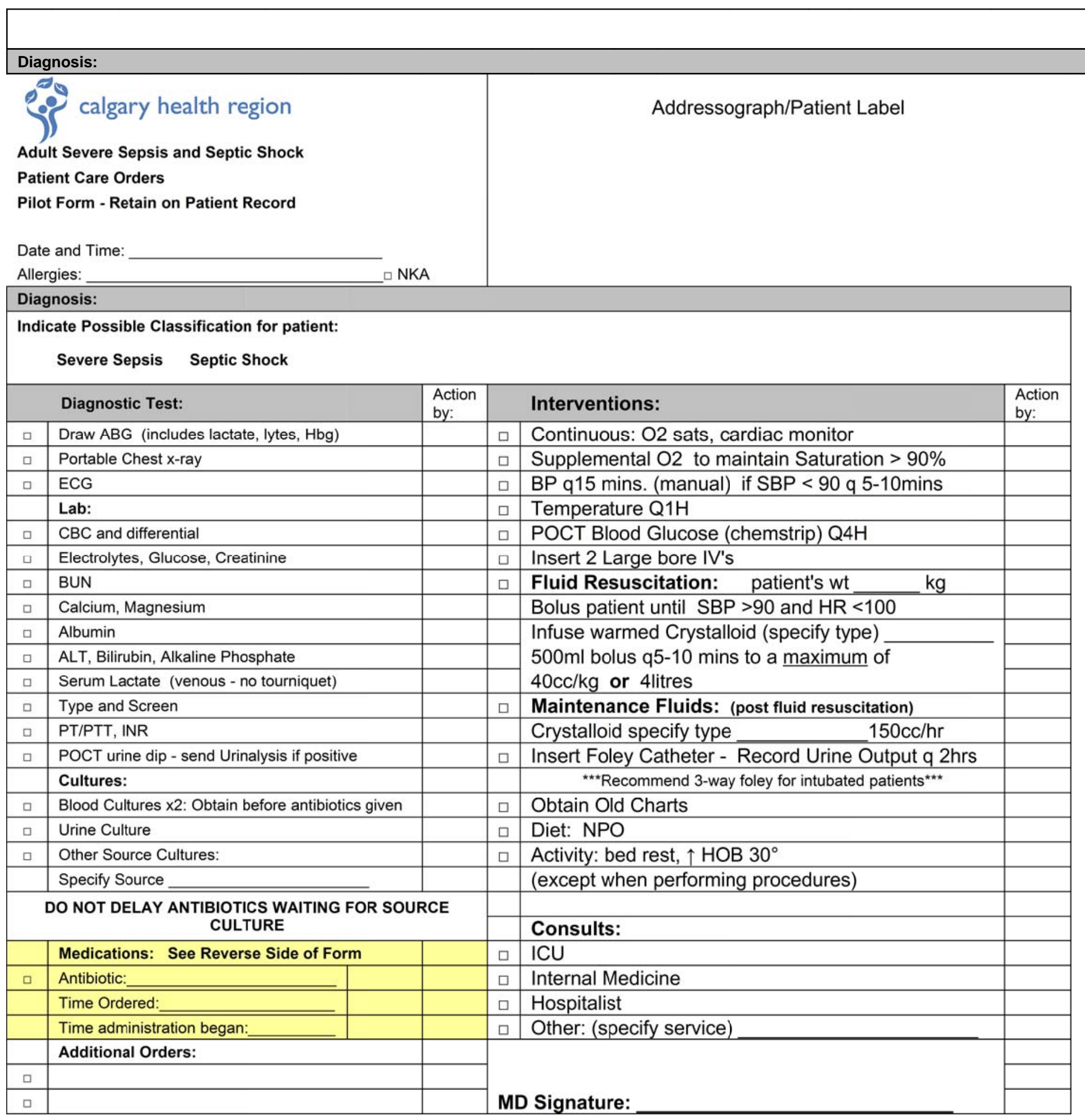

Emergency/Urgent Care Unit Manual 


\begin{tabular}{|l|l|l|l|l||}
\hline $\begin{array}{l}\text { Subject/Title: } \\
\text { SUSPECTED SEPTIC PATIENT } \\
\text { PROTOCOL ( } \geq 14 \text { YEARS OF AGE) }\end{array}$ & $\begin{array}{l}\text { Date } \\
\text { Established }\end{array}$ & $\begin{array}{l}\text { Date } \\
\text { Reviewed/ } \\
\text { Revised: } \\
2007.08\end{array}$ & $\begin{array}{l}\text { Refere } \\
\text { nce } \\
\text { No.: } \\
\text { S-4 }\end{array}$ & $\begin{array}{l}\text { Page: } \\
10 \text { of } \\
11\end{array}$ \\
\hline
\end{tabular}

\section{$* * * * *$ ALL SUBSEQUENT ORDERS ON A SEPARATE ORDER SHEET $* * * * *$}

\section{RATIONALE}

- The Surviving Sepsis Campaign ${ }^{1}$ aims to reduce sepsis mortality by $25 \%$ by 2009

- Key elements include early recognition, early antibiotic therapy and early effective resuscitation

- Effective resuscitation targets goals of adequate preload (CVP), afterload (Mean Arterial Pressure), and tissue perfusion (mixed venous oxygen concentration, lactate).

- Aggressive goal directed therapy in the first six hours after presentation of severe sepsis significantly improves mortality ( 46.5 vs $30.5 \%)^{2}$

- 1 life saved for every 6 patients treated

1. Intensive Care Med. 2004 Apr;30(4):536-55. Dellinger RP et al

2. N Engl J Med. 2001 Nov 8;345(19):1368-77. Rivers E et al

\section{Community Acquired Pneumonia}

\section{Antibiotic List:}

1. Ceftriaxone 2gm IV PLUS Azithromycin 500mg IV, OR

2. Levofloxacin $500 \mathrm{mg}$ IV

\section{Intra-abdominal Infection}

1. Piperacillin/Tazobactam $3.375 \mathrm{gm} \mathrm{IV}$, OR

2. Ceftriaxone 2gm IV PLUS Metronidazole 500mg IV, OR

3. Ampicillin $2 \mathrm{gm}$ IV PLUS Gentamicin $6 \mathrm{mg} / \mathrm{kg}$ IV PLUS Metronidazole $500 \mathrm{mg}$ IV

\section{Urosepsis}

1. Gentamicin $6 \mathrm{mg} / \mathrm{kg}$ IV OR

2. Ceftriaxone 2gm IV

\section{Meningitis}

1. Dexamethasone $10 \mathrm{mg}$ IV at or before antibiotics given

2. Ceftriaxone $2 \mathrm{gm}$ IV PLUS Vancomycin $1 \mathrm{gm}$ IV

\section{Cellulitis/Bone/Joint}

1. Cefazolin $2 \mathrm{gm} \mathrm{IV,} \mathrm{OR}$

2. Cloxacillin $1 \mathrm{gm} \mathrm{IV}$

\section{Fasciitis}

1. Clindamycin $600 \mathrm{mg}$ IV PLUS Penicillin 4 MU IV

\section{Endocarditis}

1. Ensure Blood Culture $x$ THREE are done

2. Ceftriaxone $2 \mathrm{gm}$ IV

3. ADD Vancomycin $1 \mathrm{gm}$ IV if MRSA suspected

\section{Infected Central Line}

1. Pull Line

2. Vancomycin $1 \mathrm{gm}$ IV 


\section{EMERGENCY/URGENT CARE}

UNIT MANUAL

\begin{tabular}{|l|l|l|l|l||}
\hline $\begin{array}{l}\text { Subject/Title: } \\
\text { SUSPETED SEPTIC PATIENT } \\
\text { PROTOCOL ( } \geq \mathbf{1 4} \text { YEARS OF AGE) }\end{array}$ & $\begin{array}{l}\text { Date } \\
\text { Established } \\
2006.05\end{array}$ & $\begin{array}{l}\text { Date } \\
\text { Reviewed/ } \\
\text { Revised: } \\
2007.08\end{array}$ & $\begin{array}{l}\text { Refere } \\
\text { nce } \\
\text { S-4 }\end{array}$ & $\begin{array}{l}\text { Page: } \\
11 \text { of } \\
11\end{array}$ \\
\hline
\end{tabular}

1. Piperacillin/Tazobactam 3.375gm IV PLUS Gentamycin $6 \mathrm{mg} / \mathrm{kg} \mathrm{IV}$

\section{Sepsis Source Unknown}

1. Treat for MOST likely source

2. Treat as per Intra-abdominal Infection. 